\section{$\rightarrow$}

LA-UR- $98-1161$

Approved for public release; distribution is unlimited.

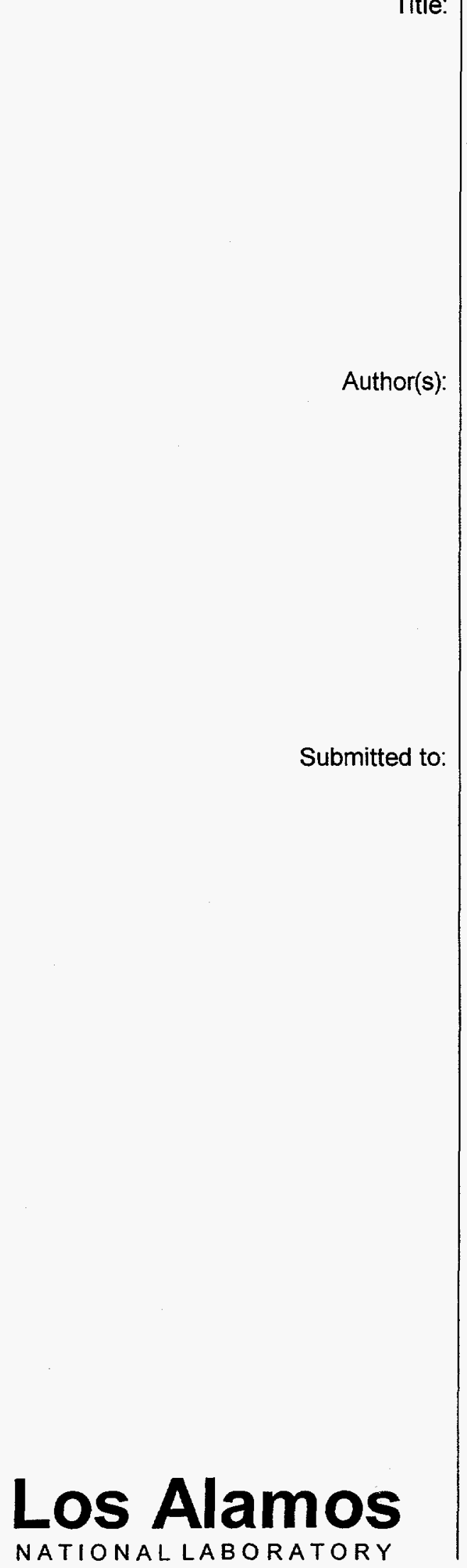

A Review of Acceptance Testing of the Los Alamos, Canberra Alpha Sentry Continuous Air Monitor (CAM)

John C. Rodgers

Health Physics Measurements Group

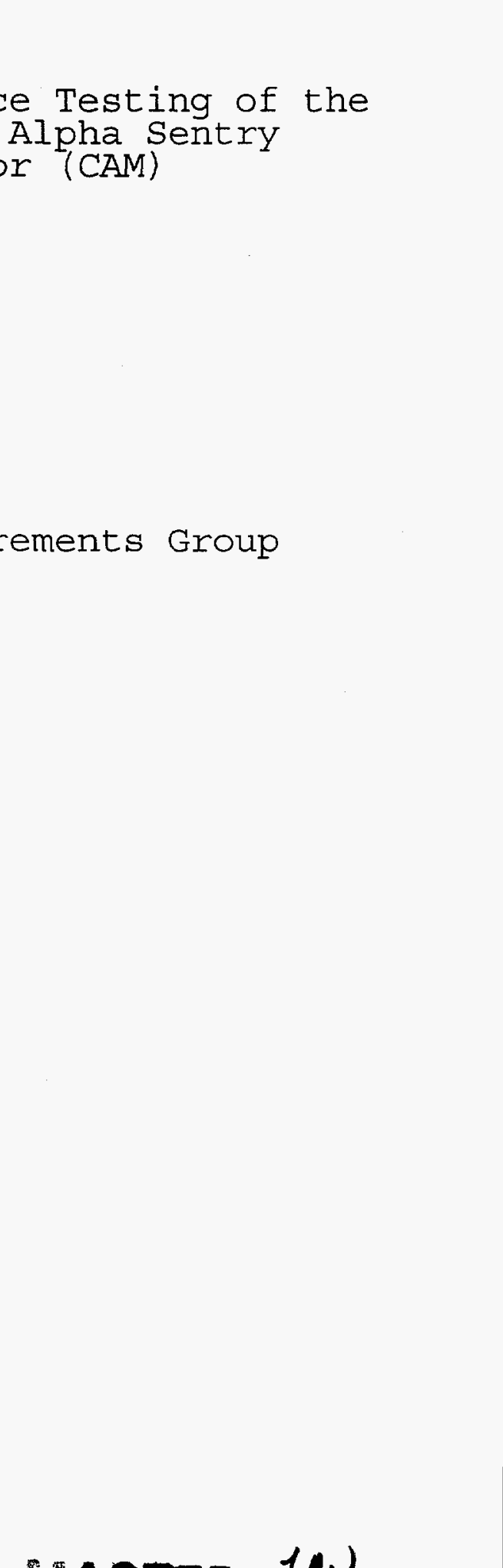

Los Alamos National Laboratory, an affirmative action/equal opportunity employer, is operated by the University of California for the U.S. Department of Energy under contract W-7405-ENG-36. By acceptance of this article, the publisher recognizes that the U.S. Govemment retains a nonexclusive, royalty-free license to publish or reproduce the published form of this contribution, or to allow others to do so, for U.S. Government purposes. Los Alamos National Laboratory requests that the publisher identify this article as work performed under the auspices of the U.S. Department of Energy. The Los Alamos National Laboratory strongly supports academic freedom and a researcher's right to publish; as an institution, however, the Laboratory does not endorse the viewpoint of a publication or guarantee its technical correctness. 


\section{DISCLAIMER}

This report was prepared as an account of work sponsored by an agency of the United States Government. Neither the United States Government nor any agency thereof, nor any of their employees, make any warranty, express or implied, or assumes any legal liability or responsibility for the accuracy, completeness, or usefulness of any information, apparatus, product, or process disclosed, or represents that its use would not infringe privately owned rights. Reference herein to any specific commercial product, process, or service by trade name, trademark, manufacturer, or otherwise does not necessarily constitute or imply its endorsement, recommendation, or favoring by the United States Government or any agency thereof. The views and opinions of authors expressed herein do not necessarily state or reflect those of the United States Government or any agency thereof. 


\section{DISCLAIMER}

Portions of this document may be illegible in electronic image products. Images are produced from the best available original document. 


\title{
A Review of Acceptance Testing of the Los Alamos/Canberra Alpha Sentry Continuous Air Monitor (CAM)
}

\author{
Prepared by: John C. Rodgers \\ Health Physics Measurements Group, ESH-4
}

\section{Background and Overview}

Los Alamos National Laboratory (LANL) undertook the design and development of a new generation of alpha continuous air monitor (CAM) instrumentation that would incorporate advanced technologies in the design of the sampling inlet, multi-channel analyzer (MCA) electronics, solid state alpha detectors, radon background interference suppression, background interference compensation and based on spectral analysis, and microcomputer based data communication, processing, storage, and retrieval. These characteristics and others were specified in detailed form in LANL Specification 4705Y (PR5-EF9-470Y, November 3, 1988), and in a subsequent Requirements Document for Continuous Air Monitor Electronics (David Nelson, February 20,1990). The CAM aerosol sampling head design emerged out of a collaboration with the Aerosol Technology Laboratory of Texas A\&M University that began in 1988 and included an evaluation of existing CAM sampling head designs, and the collaborative design and testing of an entirely new CAM head concept. An overall new CAM system design, including both sampling head and data processing and communication electronics, was successfully completed with 2 years. (Figure 1.) Following a solicitation in the Commerce Business Daily (May 18, 1990) for an industrial partner to participate through Cooperative Research and Development Agreement (CRADA) technology transfer in final development and commercialization of a new CAM, Canberra Industries, Inc. was competitively selected out of 4 bids to join with Los Alamos and Texas A\&M University to advance the prototype CAM head, electronics, and software from a laboratory device to a final manufactured product. The details of these initial development phases and copies of the pertinent materials are documented in a letter report, "A Review of the Record of Decision on LANL CAM Technology" (John C. Rodgers, HS-4-MTS-073, June 14, 1992) (Appendix A). The technical details of the design and laboratory testing of the CAM sampling head component of the system are presented in a peer reviewed technical journal paper, "A Continuous Sampler with Background Suppression for Monitoring Alpha-emitting Aerosol Particles" (A.R. McFarland, J.C. Rodgers, C.A. Ortiz, and M.E. Moore, Health Physics, Vol. 2, No. 5, May, 1992). (Appendix A) A discussion of the data processing and background compensation algorithm developed for the CAM is presented in a paper, "Performance Characterization of a New CAM System", (M. Koskelo, J. Rodgers, D. nelson, A. McFarland, and C. Ortiz, Presentation at the $22^{\text {nd }}$ DOE/NRC Nuclear Air Cleaning and Treatment Conference, August, 1992) (Appendix A). This paper also contains valuable information on the result of performance testing and intercomparisons between the laboratory prototype CAM head and the Canberra pre-production instrument. A patent has been issued on the design of the radon 
daughter interference suppression inlet screen (U.S. Patent 5,128,539), and a patent has also been granted on the novel elbow meter designed to accurately monitor sampling flow through the CAM head (U.S. Patent 5,337,603). Additional details on the many facets of the design and performance of the LANL/Canberra Alpha Sentry CAM system have been presented at numerous professional society meetings and DOE workshops. The final Canberra product description, "Alpha Sentry CAM System, August, 1993, provides a summary of the instrument component performance characteristics and features (Appendix B). The stated sensitivity of 2 DAC-hrs with a 2inch detector $\left(1700 \mathrm{~mm}^{2}\right)$ under laboratory conditions ( $1 \mathrm{pCi} / \mathrm{l}$ radon background) exceeds both the Laboratory Requirements Document sensitivity specification and the DOE 10CFR835 sensitivity requirements (8 DAC-hrs). Once a limited preproduction of Alpha Sentry CAMs had been built by Canberra, independent testing and evaluation was conducted at Los Alamos (LANL), the Inhalation Toxicology Research Institute under contract with Los Alamos, at Canberra Industries and their sub-contractors, and at the Texas A\&M University Aerosol Technology Laboratory (TAMU). The Texas A\&M tests demonstrated that the aerosol sampling characteristics of the commercial CAM are identical to those of the laboratory prototypes built at Texas A\&M University. In particular, the tests showed that the aerosol sampling performance exceeds the design goal of $50 \%$ of $10 \mu \mathrm{m}$ aerodynamic equivalent diameter particles penetrating through the inlet to the sample filter. The special tests at ITRI demonstrated that the CAM alarm response to actual plutonium aerosols at exposure levels ranging from 0 to 24 Derived Air Concentration (DAC) - hours in the presence of significant radon daughter interference was accurate and sensitive, and not susceptible to false alarm. These tests confirm that the Alpha Sentry CAM System exceeds the performance requirement of supporting an 8 DAC-hr alarm threshold while maintaining an acceptably low false alarm rate. The Los Alamos and Canberra tests were aimed particularly at ANSI type testing and functionality, but also addressed alarm functionality. These series of tests demonstrated that the Alpha Sentry CAM does meet all of the ANSI performance specifications for occupational CAM instrumentation.

\section{Acceptance Test Findings}

The ANSI air monitoring instrument standards ("Performance Specifications for Health Physics Instrumentation -- Occupational Airborne Radioactivity Monitoring Instrumentation", N42.17B) specify performance criteria and testing procedures for instruments and instrument systems designed to continuously sample and quantify airborne radioactivity in the workplace. Although the intent of the standard is to provide performance testing criteria for type testing, it is appropriate to evaluate the performance of a new instrument such as the Alpha Sentry against certain of these criteria for purposes of an acceptance test based on stated specifications and the Los Alamos CAM Requirements document. The following discussion provides an overview of the results of these tests, as they pertain to instruments designed to detect alpha-emitting radionuclides in particulate form: 
Section 3.0 The general test procedures of this section were adhered to in these tests. The standard test conditions of temperature, humidity, pressure, and the like applied during tests. The effects of statistical fluctuations were minimized by sufficient count times and number of readings.

Section 4.0 The characteristics of the Alpha Sentry CAM design meet the Los Alamos specifications and the Texas A\&M laboratory prototype instrument, as determined by inspection during tests of pre-production units at LANL and TAMU (Section 4.2.1).

The design of the CAM conforms to the definition of a particulate radioactivity monitor (4.1.3). It is designed to continuously sample workplace (or effluent stack) air with particulate collection onto a filter that is continuously monitored by a solid-state radiation detector sensitive to alpha particle emissions.

The Alpha Sentry Manager (ASM) controller/user-interface part of the system (see Fig. 1, and also Canberra Nuclear Alpha Sentry Specifications, Appendix B) contains the data processing computer and user interface components, including an LCD display and keyboard. The Units of Readout (Section 4.3) are user selectable. All instrument controls are selected via the keyboard or by a communication link (RS-232 protocol) with an external PC portable computer. An additional RS-485 communication link can be established between the ASM and a host computer that is remotely located in a command / control center environment, and supports networking all of the CAMs in a facility. Window environments in either device provide the user with clearly defined setup options. The stated functionality of each of the user selectable functions has been verified in Los Alamos laboratory tests (ANSI Section 4 Summary attached, Appendix B). The sampling head itself has no controls or display other than LED signal lights, and the audible and visual annunciators that signal an alarm condition. (Note the "Alarm" and "Count" LEDs on the CAM head, Figure 1. Not shown in this figure is the optional red strobe alarm light and the annunciator that mount on the top plate.)

The Section 4 tests conducted by Canberra Nuclear (AC Power Voltage and AC Power Frequency, Section 4.7) are shown in Table 1, Appendix B. Both test outcomes were well within ANSI limits.

\section{Sections 5.1 through 9.6}

The ANSI tests of CAM functionality, including electronic criteria, radiation response, interfering responses, and air circuit criteria are numerous and complex. Those conducted at Los Alamos in these categories were not the complete suite, but tended to focus on instrument calibration, DAC-hr sensitivity, and radiation detection functionality under environmental test chamber conditions and certain field trial conditions. However, the Canberra tests in these categories followed the formal ANSI test procedures. The Los Alamos test results are summarized in Appendix B. The Canberra test results are also summarized in Table 1, Appendix B. A complete 

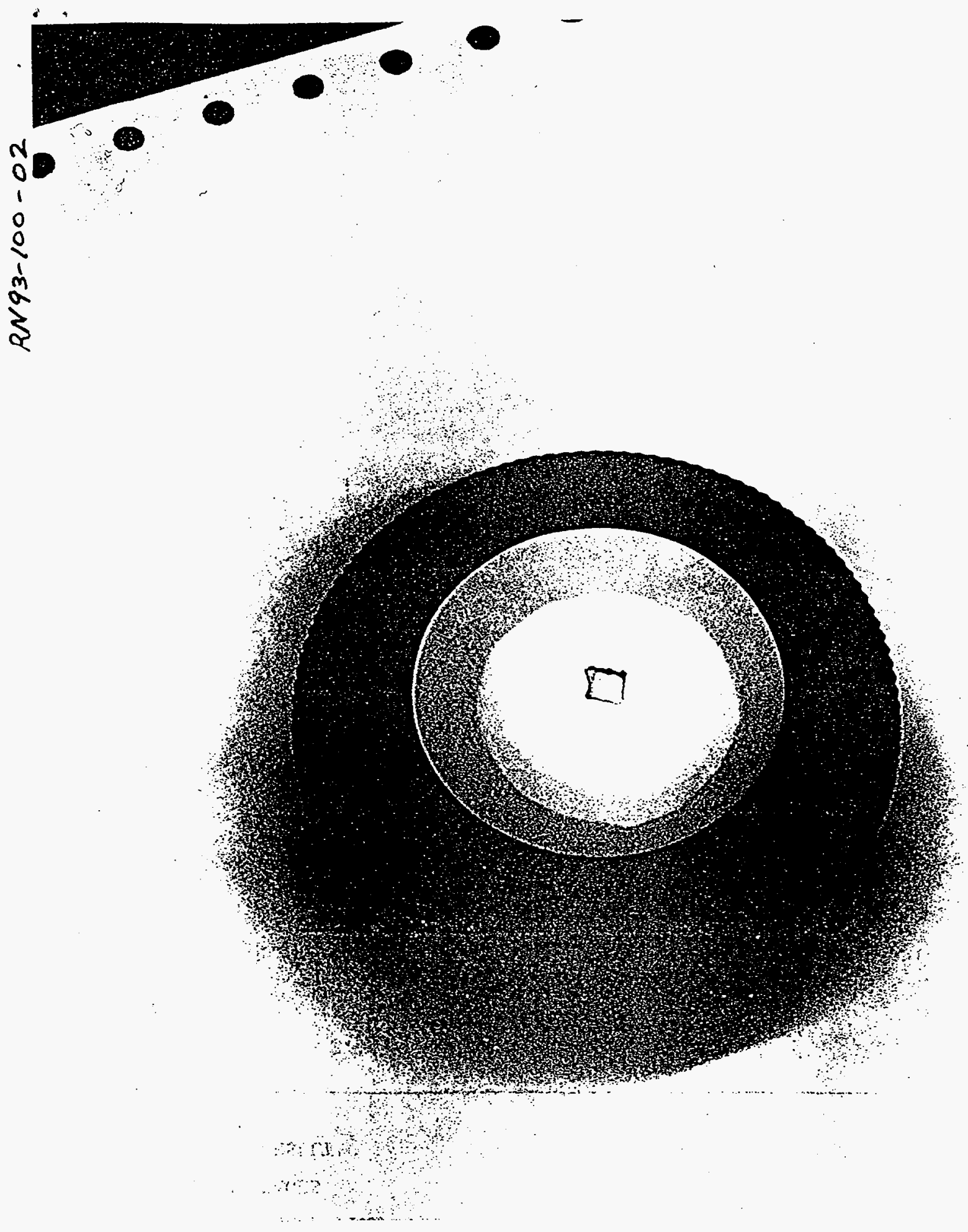

Figure 2. Los Alamos Special Source-plus-filter Concept

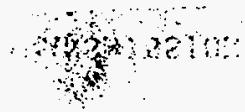




\section{Pu-238 DAC-hr Accuracy Test Series}

Los Alamos TA-55 PF-4 Decon Room

Conventially True Exposure (not incl. bkg.): 9.8 DAC-hr

Mean Observed Exposure: 10.7 DAC-hr

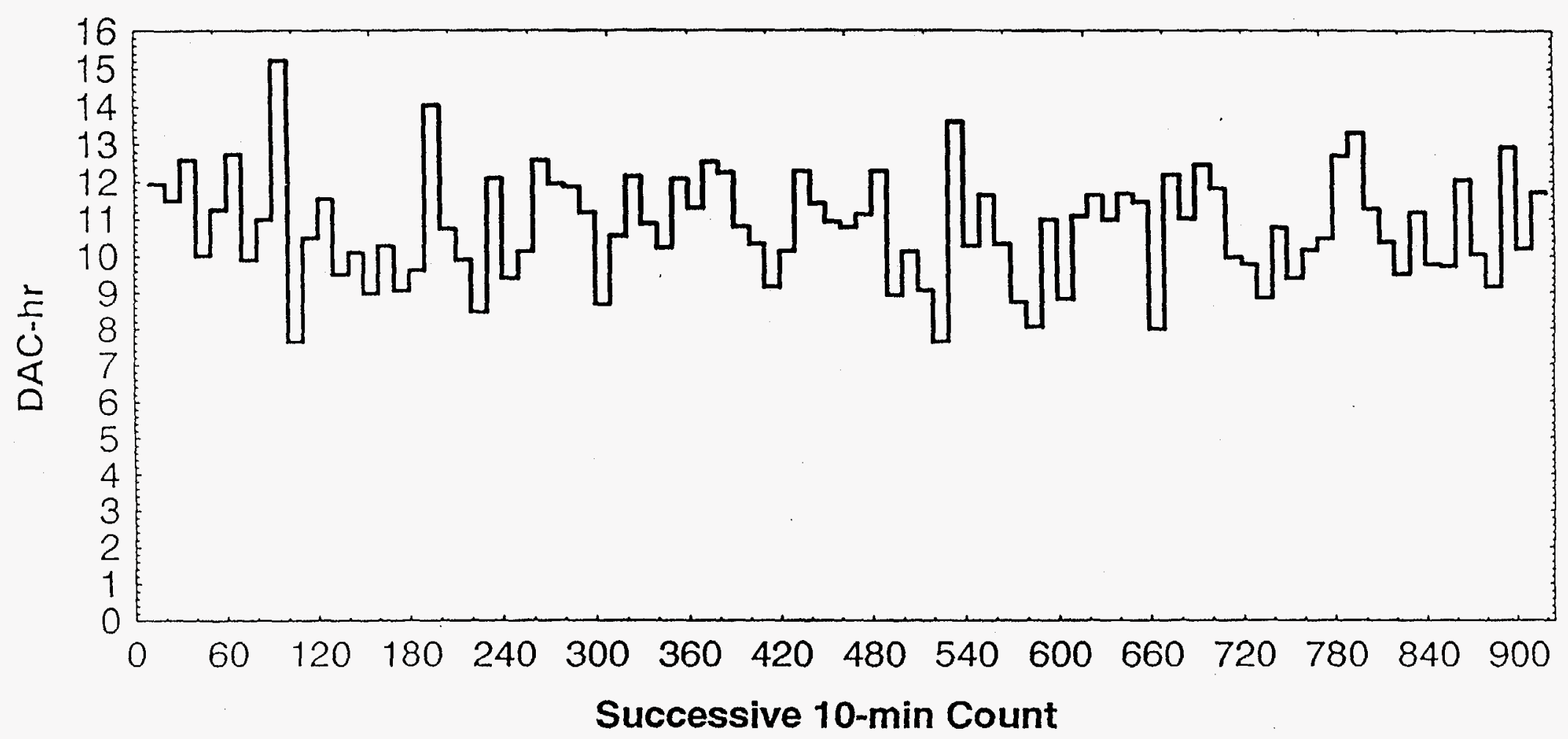

Figure 3. 
record of the data from these tests, "Alpha Sentry CAM System Performance Testing Book 1, and Book 2, 1993" is maintained in Group ESH-4.

Some of the Los Alamos tests of DAC-hr sensitivity involved preparation of a special source that allows simultaneous collection of radon daughter background and at the same time, exposure of the detector to a calibrated amount of plutonium alpha activity. An example of such a special source filter is shown in Figure 2. The result is an excellent surrogate of actual plutonium exposure in the presence of radon interference. Tests with this special source provided determinations of accuracy (6.2), radiation type and energy (6.4), and response to unwanted radiations (6.5) (i.e., radon background). The results of a test with the source set to yield an approximate 10 DAC-hr exposure yielded acceptable alarm responses in repeated measurements with the alarm threshold set at 9.8 DAC-hr. A plot of the DAC-hr log for a 15-hour run are shown in Figure 3. The Canberra tests of electronic criteria (Section 5.0 series), electromagnetic interference (Section 7.0 series) and environmental criteria (Section 8.0 series) all showed instrument responses within the expected ranges and limits. Los Alamos environmental chamber tests (temperature and humidity effects) confirmed the 8.0 series findings of Canberra. An example of the instrument response in the Los Alamos chamber is shown in Figure 4.

\section{Section 9.7}

The tests of this section concern particle collection by the CAM head. General tests of the particle collection efficiency of the Alpha Sentry CAM head were performed by Texas A\&M University that confirm that the particle transmission characteristics of the commercial instrument match the performance of the laboratory prototype.

Much more specific plutonium exposure response tests (Section 6.0 series) and aerosol tests (Section 9.7) were conducted by the Inhalation Toxicology Research Institute (ITRI). The performance and sensitivity tests involved exposure of the CAM to combinations of ${ }^{239} \mathrm{Pu}$ and radon progeny in particulate form. As stated in the summany of the ITRI report (Appendix C), the results of these tests with actual plutonium aerosols demonstrate that the CAM meets or exceeds the 8 DAC-hr sensitivity requirement. Specifically, the ITRI study findings include the following:

- Collection efficiency for ultra-fine particles is $89 \%$, and for $10 \mu \mathrm{m}$ particles is $68 \%$, both of which exceed the target of $50 \%$ efficiency (|TR| Table 6).

- Homogeneity of particle deposition on the sample filter is within $10 \%$ of the mean (ITRI Table 6).

- The ratio average reported Pu concentration to actual Pu concentration remained close to unity ( $100 \pm 20 \%$ of actual) under radon progeny background interference concentrations ranging from zero to $4 \mathrm{pCi} /$ (ITRI Table 4 and Table A4). 


\section{MAY 4,1993 ENVIROMENTAL TEST 5-MIN. 20TO50C@+10C/HR,20TO-10C@-10C/HR}

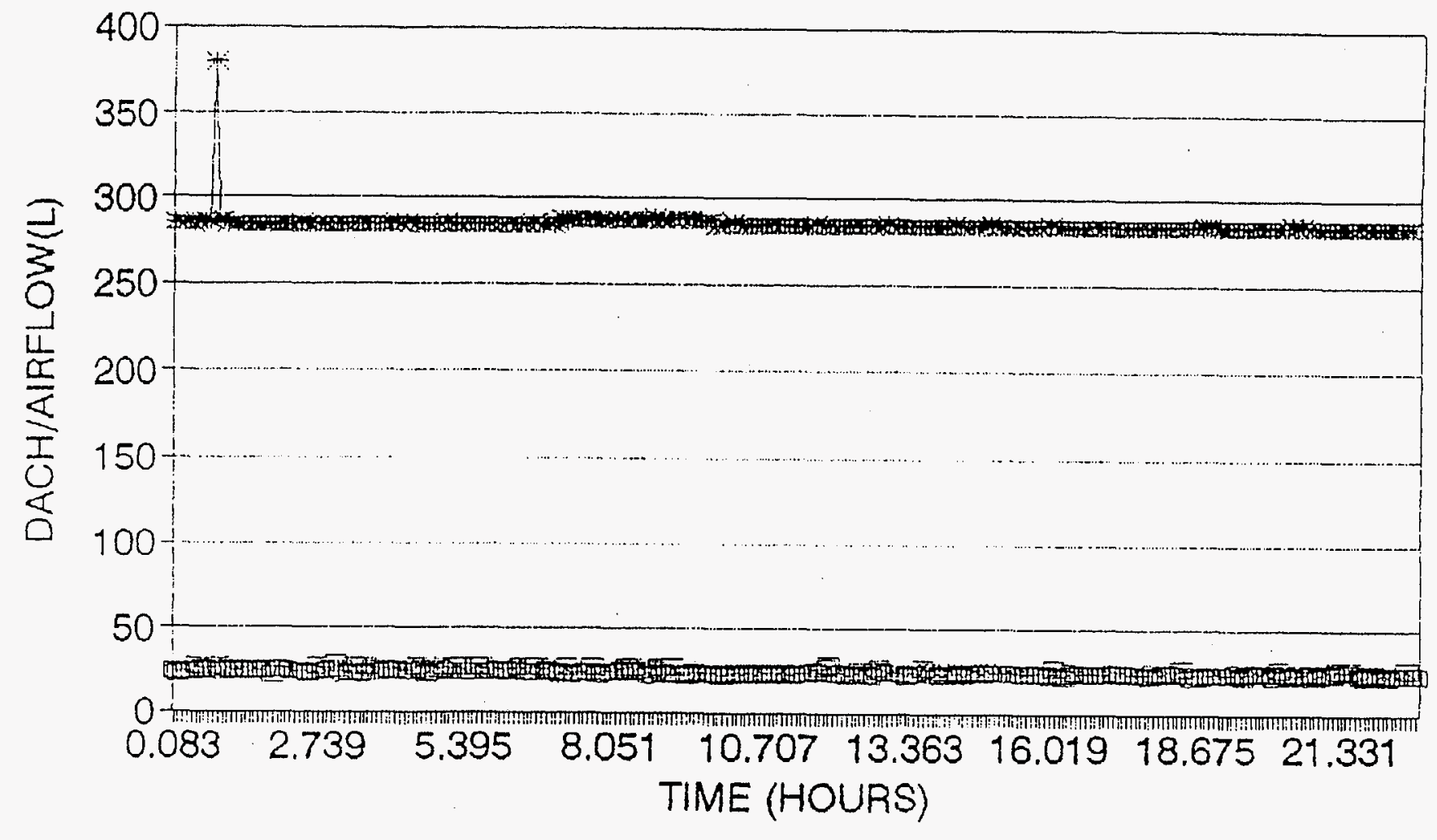

$\square-\mathrm{DACH} \quad \rightarrow$ AIRFLOW(L)

Figure 4. Environmental Chamber Test of the Alpha Sentry CAM System 


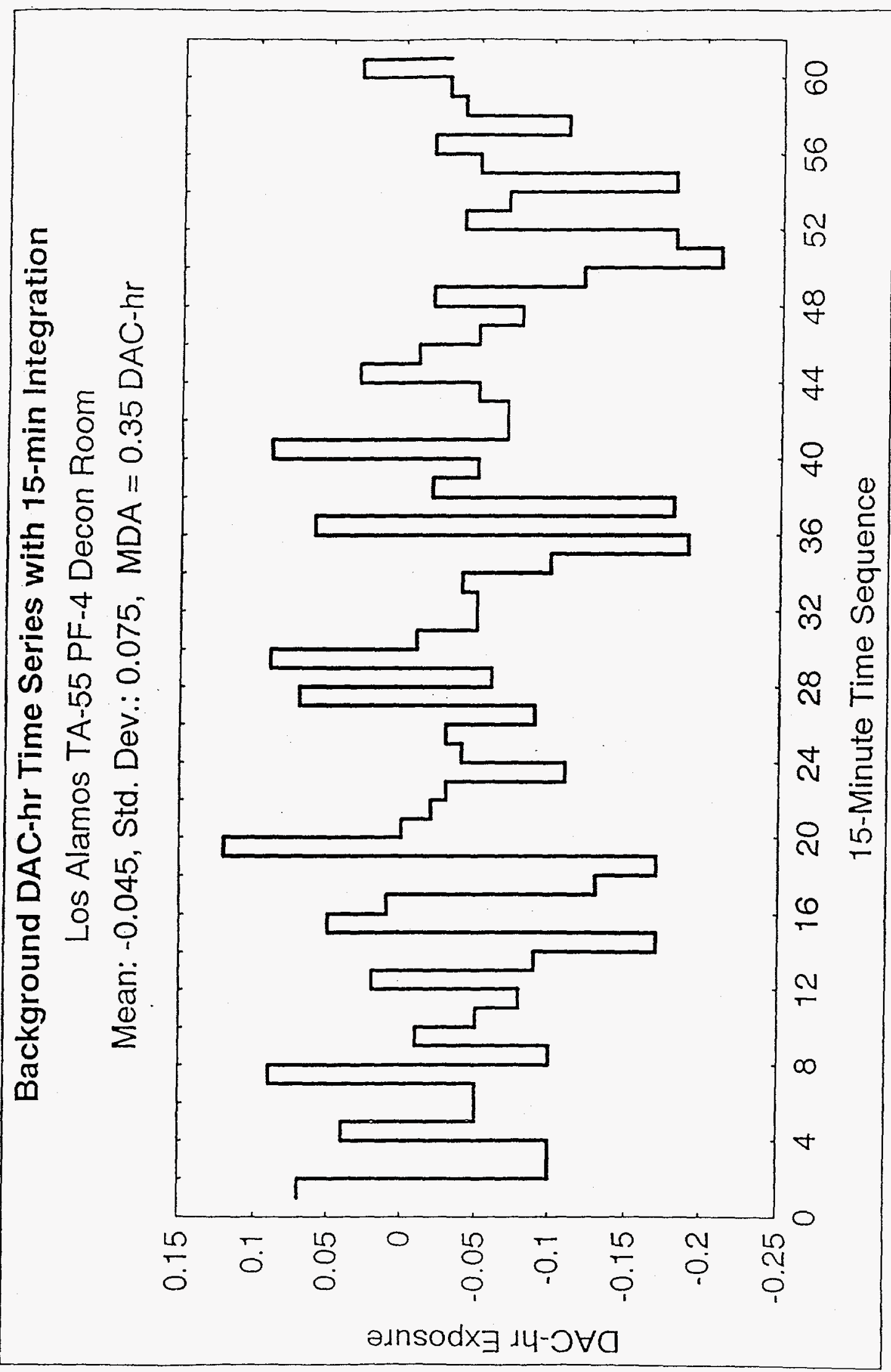

